\title{
Agreement Properties and Word Order in Comparative Bantu
}

\author{
Yukiko Morimoto \\ ZAS, Berlin
}

Agreement is traditionally viewed as a cross-referencing device for core arguments such as subjects and (primary) objects. ${ }^{1}$ In this paper, I discuss data from Bantu languages that lead to a radical departure from this generally accepted position: agreement in a subset of Bantu languages cross-references a (sentential) topic rather than the subject. The crucial evidence for topic agreement comes from a construction known as subject-object ( $\mathrm{S}-\mathrm{O}$ ) reversal, where the fronted patient agrees with what has uniformly been taken to be a 'subject marker'. The correct analysis of S-O reversal as a topic construction with 'topic agreement' explains a range of known facts in the languages in question. Furthermore, synchronic variation across Bantu in the presence/absence of S-O reversal and in the properties of the (topic/subject) agreement marker suggests a diachronic path from topic to subject marking. The systematic variation and covariation in the syntax of Bantu languages and the historical picture that it offers would be missed altogether if we continue to reject the idea that the notion of topic can be deeply grammaticized in the form of agreement.

\section{Introduction}

One of the most pronounced and most studied aspects of Bantu grammar is the rich classes of agreement morphology. One of the most detailed studies of Bantu agreement within generative syntax is offered by Bresnan and Mchombo (1987), who focus on the properties of subject and object marking in the Eastern Bantu language Chichewa. They show that in Chichewa the subject marker (SM) functions both as grammatical agreement and as a topic-anaphoric pronoun, whereas the object marker (OM) functions only as a promoninal argument. Thus

\footnotetext{
${ }^{1}$ I am grateful to Peter Sells for discussions on earlier versions of this work, to Alxandre Kimenyi and Jeanine Ntihirageza for assistance with Kinyarwanda data and Juvenal Ndayiragije for Kirundi data. I also benefitted from useful comment and suggestions from the editors of this volume, although unfortunately some issues the editors have raised have to be left for future work. Thanks also to Christian Geng for editorial assistance. Any remaining errors or misrepresentations are my own.
} 
in the absence of the OM, the object NP must be licensed positionally within VP. They also observe that the facts about object marking in Chichew a do not automatically extend across the whole Bantu family. For example, Swahili requires object marking for definite objects (cf. Bokamba 1981; also Wald 1979); in the Imithupi dialect of Makua studied by Stucky $(1981,1983)$, the OM is obligatory for the human classes (classes $1 \& 2$ ) even when the overt object NP is not topical. Morimoto (2002) discusses these facts under the general concept of differential object marking (DOM; cf. Bossong 1985) and suggests that these cross-linguistic data can be viewed as various stages of the gradual loss of the inflectional morphology and rise of positional licensing for objects.

A closer look at subject marking in other Bantu languages also reveals that facts in those languages diverge from the findings reported by Bresnan and Mchombo on Chichewa. Bresnan and Mchombo (p.778) note that in Dzamba, although all arguments inside VP can be questioned in situ, as in (1b), the subject cannot be questioned in its initial position, as shown by the ungrammaticality of (1c). In order to question the subject, a relative clause must be used, as shown in $(1 \mathrm{~d}){ }^{2}$

(1) a. ó-Nebo a-imol-aki ó-Biko e-kondo loo mé.

Dzamba

'Nebo told Biko a story/tale today.'

b. ó-Nebo a-imol-aki nzányí e-kondo loo mé?

(lit.) 'Nebo told who a story today?'

c. *nzányí a-imol-aki ó-Biko e-kondo loo mé?

'Who told Biko a story today?'

d. ó-Moto ó-wimol-aki ó-Biko e-kondo loo mé nzányí?

(lit.) 'The person who told Biko a story today is who?'

Based on such data, Bresnan and Mchombo speculate that unlike Chichewa, in which the subject can be questioned in its initial position, in Dzamba, all subject NPs must necessarily be grammaticized topics. They further note, citing Bokamba (1981), that Dzamba has 'nominal pre-prefixes' which are obligatory on definite NPs. For example, in (1), we have the pre-prefix $o$ - on the proper nouns $(o-N e b o, o ́-B i k o)$. Such pre-prefixes are obligatory on subjects. This supports their hypothesis that all subjects are obligatorily grammaticized top-

\footnotetext{
${ }^{2}$ In the examples taken from published sources, I have kept the original use of tones and glosses, which, in some cases, results in inconsistency throughout this paper. For example, a final vowel (FV) in Chichewa (e.g. Bresnan and Mchombo 1987) is glossed as ASP(ECT) in Kinyarwanda (e.g. Kimenyi 1980); the morpheme $r a$ is glossed as anti-focus (AF) in Kirundi (Ndayiragije 1999) but present tense (PRES) in Kinyarwanda (e.g. Kimenyi 1980).
} 
ics. Taking this initial observation as a starting point, in this paper I explore the idea that what has uniformly been taken to be the subject marker in Bantu languages in fact represents two types of agreement system: subject versus topic agreement.

The crucial evidence for topic agreement in Bantu languages comes from a construction known as subject-object (S-O) reversal in a subset of Bantu languages, exemplified in (2) from Kinyarwanda (Kimenyi 1980). ${ }^{3}$ In the canonical SVO sentence in (2a), the relevant agreement marker $a$ (boldfaced) agrees with class 1 of the logical subject Umuhuûngu 'boy'. In the reversal sentence in (2b), the agreement marker $k i$ agrees in class 7 of the lower argument igitabo 'book'. As shown in the translation, the fronted patient ('book') is a topic, and the postverbal logical subject receives a (contrastive) focus interpretation. ${ }^{4}$

(2) a. Umuhuûngu a-ra-som-a igitabo.

SVO

1boy 1-PRES-read-ASP 7book

'The boy is reading the book.'

b. Igitabo ki-som-a umuhuûngu.

OVS

7book 7-read-ASP 1boy

'The boy (FOC) is reading the book (TOP)'

Kinyarwanda

The agreement pattern we see in $(2 b)$ is the unique property of this construction that raises the question as to the grammatical relation of the fronted patient to the verb. Unlike the more familiar left-dislocation, the object marker agreeing with the fronted patient is never present in S-O reversal, as shown the contrast between S-O reversal (3a) and left-dislocation (3b) (Kimenyi 1980:192, ex.(4))..$^{5}$

\footnotetext{
${ }^{3}$ The data without citation have been generously provided by Alexandre Kimenyi for Kinyarwanda and Juvénal Ndayiragije for Kirundi. Tones are unfortunately left out in the elicited examples.

${ }^{4}$ The abbreviations used in the glosses are as follows: $\mathrm{AF}=$ anti-focus, $\mathrm{ASC}=$ associative, $\mathrm{ASP}=$ aspect, $\mathrm{Dz}=$ Dzamba, $\mathrm{ENCL}=$ enclitic, exp=experiencer, $\mathrm{FV}=$ final vowel, IMPERF=imperfect, IM.FUT=immediate future, INDIC=indicative, INF=infinitive (=class 15), Krw=Kinyarwanda, $\mathrm{Kdi}=\mathrm{Kirundi}, \mathrm{LOC}=$ locative, number $\mathrm{N}=$ noun class, $\mathrm{OM}=$ object marker, PASS=passive, PERF=perfect, PRES=present tense, PST=past, SM=subject marker $\mathrm{TM}=$ topic marker.

${ }^{5}$ The $\mathrm{S}-\mathrm{O}$ reversal example in (3a) is constructed by the author.
} 
(3) a. Igitabo ki-som-ye úmwáana.

S-O reversal

7book 7-read-ASP 1child

'The child (FOC) is reading the book (TOP)'

b. igitabo, úmwáana a-ra-gi-som-ye.

Object left-dislocation

7book 1child 1-PRES-7-read-ASP

'The book, the child is reading it.'

Kinyarwanda

There are two possible solutions for the agreement pattern. The predominant solution has been to maintain the standard assumption about agreement that it licenses core argument functions such as subjects and (primary) objects. Under this assumption, the agreement marker in question must be a subject marker; S-O reversal such as $(2 b)$ is then a grammatical-relation changing operation whereby the patient gets linked to the grammatical subject, and the logical subject to the grammatical object. I refer to this solution as the subject analysis. An alternative solution, referred to as the topic analysis, assumes that no grammatical relation change takes place in S-O reversal. Rather, the agreement marker $(k i$ in $(2 b))$ is analyzed as a topic marker licensing the topical object. These two alternative solutions naturally lead to diverging predictions. I show evidence to support the topic analysis and argue that the topic function is indeed among the functions that can trigger agreement in so-called topic-prominent languages like Bantu. ${ }^{6}$

The discussion in the rest of the paper proceeds as follows. In section 2, I review some arguments for the previously proposed subject analysis, and point out why the analysis, while being able to maintain the traditionally accepted view of agreement, is nonetheless untenable for empirical reasons. In section 3 I provide the topic analysis within the constraint-based framework of LexicalFunctional Grammar (LFG; Bresnan 1982, 2001, Dalrymple, Kaplan, Maxwell, \& Zaenen 1995). In section 4 I try to relate the data on S-O reversal and other correlating facts to the historical path these languages apparently have undergone with respect to their agreement system. The final section summerizes the discussion and points out remaining issues for further research.

\footnotetext{
${ }^{6}$ The topic analysis of S-O reversal argued in the present work stems from a discussion I had with Joan Bresnan (July 1999) in relation to the observation that in a subset of Bantu languages such as Dzamba in (1), the subject is always a grammaticized topic (noted in Bresnan and Mchombo 1987). I benefitted particularly from our discussion on the systematic differences between the two similar constructions-locative inversion (Bresnan and Kanerva 1989, Bresnan 1994) and S-O reversal.
} 


\section{Against the Subject Analysis of Reversal}

Earlier work on S-O reversal (e.g. Bokamba 1976, 1979, 1985, Kimenyi 1980, 1988, Morimoto 1999) has generally assumed that the construction involves grammatical relation change, mainly due to the fact that the preverbal patient in reversal apparently triggers subject agreement: the patient (object) is fronted to the subject position and assumes the subject function, and the agent (logical subject) is postposed to the VP-internal object position. The grammatical function (GF) reversal analysis is somewhat analogous to the analysis of inversion in other languages: English, Chichewa, and Chishona, for example, exhibit inversion of the theme subject and locative complement (e.g. Out of the bushes appeared a giant bear; cf. Bresnan and Kanerva 1989, Harford 1990, Bresnan 1994); Sesotho and Setswana additionally allow inversion that involves (intransitive) unergative predicates (e.g. equivalent of In the field are grazing the cattle; see Machobane 1995, Demuth and Mmusi 1997, Lødrup 1999). In these constructions, the preverbal locative is analyzed as the grammatical subject and the logical subject in postverbal position as object, inducing a grammatical relation change; see Morimoto (1999) for an earlier OT account of all three language types including S-O (agent-patient) reversal in Kirundi and Kinyarwanda. The postverbal agent in S-O reversal has also been analyzed not as an object but as a demoted argument (e.g. chômeur in Kimenyi's (1980) analysis in Relational Grammar). Studies within the Principles and Parameters approach have analyzed S-O reversal as involving raising of the object to some functional projection usually reserved for the subject (e.g. SpecIP in Kinyalolo (1991), SpecTP in Ura (1996), Ndayiragije (1999)) and verb raising (to I or T). The logical subject either remains in its VP-internal position (cf. Kinyalolo, Ura) or raises to a specifier of FocusP above VP (cf. Ndayiragije). The latter (FocusP) alternative is intended to capture the focalization effect of this construction.

Apart from agreement, however, little evidence has been provided for the grammatical function status of the reversal arguments. Kimenyi (1980), for example, proposes that S-O reversal is a type of "subjectivization process" akin to passive: the non-agent argument canonically realized as a non-subject is realized as subject, and the logical subject is demoted. The demotion analysis is supported by the observations that the postverbal agent cannot be relativized, passivized, clefted or pronominalized. These are taken to be standard diagnostics for termhood within Relational Grammar adopted in Kimenyi's work. Kimenyi, however, admits that the preverbal NP lacks the properties of the usual subjects apart from agreement: "NPs advanced to subject by the [S-O] reversal rule do not acquire the properties of basic subjects, such as raising, deletion 
under identity, and $h a$-insertion; the only subject property they acquire is verb agreement" (Kimenyi 1980:145).

Despite the apparent formal similarities between locative inversion and S-O reversal and attempts at a unified analysis of these phenomena, I show that there are several advantages for not adopting the subject analysis, and that the alternative analysis pursued in the present work which crucially relies on the grammaticized notion of TOPIC enables us to explain a broader range of related facts. The correct analysis of S-O reversal is critical to the understanding of the agreement systems in Bantu. Although in my analysis I assume that there is no actual GF "reversal", I will continue to refer to this construction as S-O reversal for descriptive purposes.

\subsection{Lack of Evidence for Grammatical Relation Change}

In the studies of locative inversion in Chichewa and English, Bresnan and Kanerva (1989) and Bresnan (1994) apply a number of syntactic tests for subjecthood and show conclusively that preverbal the inverted locative is indeed the grammatical subject, supporting their view that locative inversion involves grammatical relation change. Here I briefly consider VP attribution, gapping in coordinate structure, and subject-to-subject raising. I then comment on each test with respect to Kirundi and Kinyarwanda, for which elicited (analogous but not identical or even comparable) data are available, only to point out that these tests cannot be reliably used to show anything about the grammatical status of the preverbal patient in S-O reversal.

Control of Attributive VPs: Bresnan (1994:93 ex (58)) shows that Chichewa has a non-finite verb that can be used to modify NPs, as in (4).
m-sodzi $\quad[V P$ W-ó-ík-á
1-fisherman 1-ASC.INF-put-FV 10.fish 163 -chair
'a fisherman putting fish on the chair'
b. nsómbá [ $V P$ Z-ó-1́k-1́-ídw-á pá m-pando]
10.fish 10-ASC.INF-put-PASS-FV 163 -chair
'fish being put on a chair'

nsómbá pa m-pando]

Chichê̂a

In both active and passive examples in (4), the subject is modified by the infinitival VP. In Chichewa locative inversion, Bresnan (p.94, ex (59)) shows that the inverted locative subject can also be modified by a non-finite VP: 
(5)
mi-kângo
18-9.forest 18-ASC.INF-live-FV 4-lion
'in the forest where there live lions'

Chichê̂a

The example in (5) thus provides evidence for the subject status of the inverted locative in Chichewa.

Extraction out of Coordinate Constituents: Extraction out of coordinate constituents is used to distinguish among grammatical functions. The generalization that holds for English is that "subject gaps at the top level of one coordinate constituent cannot occur with any other kind of gap the other coordinate constituent", as succinctly stated in Bresnan 1994:98 (cf. Williams 1977, Gazdar 1981, Falk 1983, Woolford 1987). This is illustrated by the examples in (6) (Bresnan 1994:98, exs (71)-(72)).

(6) a. She's someone that _ loves cooking and _ hates jogging.

b. She's someone that cooking amuses and jogging bores

(7) a. *She's someone that cooking amuses _ and _ hates jogging.

b. She's someone that cooking amuses _ and I expect _ will hate jogging. (O-embedded S)

Bresnan (1994) shows how the inverted locative in locative inversion in English (e.g. Out of the bushes appeared a monster) observes the same constraint with respect to extraction from coordinate constituents (Bresnan 1994:98, exs (73)(74)). This test has been used to test for subjecthood in other languages as well (cf. Joshi 1993 for Marathi, Kroeger 1993 for Tagalog), as this allows us to distinguish between subjects and non-subjects.

(8) a. That's the old graveyard, in which _ is buried a pirate and _ is likely to be buried a treasure. (subj-subj)

b. That's the old graveyard, in which workers are digging _ and a treasure is likely to be buried _.

(nonsubj-nonsubj)

(9) a. ??That's the old graveyard, in which workers are digging _ and they say _ is likely to be buried a treasure.

(nonsubj-subj)

b. That's the old graveyard, in which workers are digging and they say is buried a treasure.

(obl-embedded subj)

These examples, then, constitute, evidence that the inverted locative is the gram- 
matical subject.

Raising: Bresnan and Kanerva (1989:14) note that Chicheŵa has very few subject raising predicates, but nonetheless report one case of raising of the locative subject of the infinitive:
(10) ... pa-chi-dzala pá-fúna
ku-túkúmbuká chi-nthu ...
16-7-rubbish pit 16-IM.FUT-want INF-emerge 7-thing
'... there seems to be something coming out of the rubbish pit ...'

Though not reflected in the English translation, the form of the sentence in (10) is locative inversion like the English From the rubbish pit seems to be emerging something. Since such raising is universally restricted to the grammatical subject of the infinitive, the example in (10) confirms the subject status of the inverted locative.

S-O Reversal Languages: As it turns out, these tests for subjecthood that are successfully applied for the conclusive results in Chichewa and English are not applicable to the reversal languages, Kirundi and Kinyarwanda.

First, in Kirundi, there is no construction analogous to VP attribution in Chichewathat shows subject control. The closest construction in Kirundi is a clausal adjunct that translates to something like "once he has finished buying ..." or "after having bought ...", according to Ndayiragije (p.c. May 2000). ${ }^{7}$ Second, extraction out of coordinate constituents fails to show anything about grammatical functions in Bantu languages for obvious reason: whenever there is a gap (null elements), the subject/object agreement morphology on the verb functions as topic-anaphoric agreement. Hence there can never be a real gap in the coordinate structure. Lastly, Kirundi and Kinyarwanda simply have no subject raising predicates such as seem, expect, and likely.

In short, the standard tests for subjecthood illustrated above for Chichewa and English all fail to apply to the reversal languages (Kirundi and Kinyarwanda) due to the lack of comparable constructions/verb types.

\subsection{Unexplained Facts}

The subject analysis put forth by various researchers also leaves some facts unexplained. Here I focus on the properties of the postverbal agent in S-O reversal, and variation across Bantu languages in the properties of agreement.

\footnotetext{
${ }^{7}$ See Morimoto 2000:155 for the relevant data.
} 


\section{The postverbal agent has no object properties}

One of the puzzling facts that remain unexplained under the subject analysis is that the postverbal agent of a reversal sentence does not display usual object properties. For example, it can neither be relativized (11) nor promoninalized (12). ${ }^{8}$

(11) *N-kund-a umuhuûngu igitabo ki-som-a.

Kinyarwanda

I-like-ASP 1boy 7book 7-read-ASP

[Intended as] 'I like the boy (FOC) who is reading the book (TOP).'

[Interpreted as] 'I like the boy that the book is reading (by magic)'

(12) a. Ba-ra-gi-som-a.

2-AF-7-read-ASP

'They are reading it.'

b. Cyi-(ra)-ba-som-a.

7-(AF)-2-read-ASP

\#'It is reading them.'

*'They (FOC) are reading it (TOP).'

(non-reversal reading)

(reversal reading)

The postverbal agent is also not in the canonical, immediately postverbal, object position. In (13a), the postverbal agent is positioned after the adverbial phrase buhurobuhuro 'slowly', presumably adjoined to VP. Placing it in the canonical object position inside VP results in ungrammaticality as illustrated in (13b). This postverbal agent is therefore neither positionally nor morphologically licensed as the grammatical object.

(13) a.
buhurobuhuro Yohani.
book 7-PAST-read-PERF slowly John
'John (FOC) read the book (TOP) slowly.'

Kirundi

b. *Ibitabo bi-a-som-ye Yohani buhurobuhuro.

The postverbal logical subject also could not be a demoted oblique as analyzed by Kimenyi (1980): in the languages considered here (e.g. Kirundi, Kinyarwanda, Dzamba), oblique arguments are generally marked by prepositions

\footnotetext{
${ }^{8}$ The ungrammaticality of example (11) does not improve even if we add an object marker corresponding to the relativized head noun umuhuûngu 'boy' or the correct relative tone marking on the verb inside the relative clause, as shown below.

(i) a. *N-kund-a umuhuûngu igitabo ki-mu-som-a.

b. *N-kund-a umuhuûngu igitabo ki-sóm-a.

Thanks to Jeanine Ntihirageza for this additional information.
} 
such as $n^{\prime}$ in (14) from Kinyarwanda. If the postverbal agent were a demoted oblique, this would be an odd exception, for which no explanation has been provided. ${ }^{9}$
(14) a. Úmwáalímu a-ra-andik-a
n’ ííkárámu. teacher 1-PRES-write-ASP with pen
'The teacher is writing with a pen.' child 1-PST-cry-ASP with sorrow much 'The child was crying with much sorrow.'
b. Úmwáana y-a-rir-aga n’ âgahiinda keênshi.

Kinyarwanda

Kimenyi (1980)

If the postverbal agent is not an object or oblique, then we are left with the assumption that it is the grammatical subject.

\section{Reversal and non-reversal languages show varying properties of agreement}

A closer look at the properties of the agreement morphology in question across the Bantu family reveals systematic variation that correlates with the presence/absence of S-O reversal. The relevant data include the patterns of $w h$ questions and idiomatic expressions involving the verb and object. These data both point towards the different properties of the agreement morphology across Bantu.

Wh-elements: $W h$-phrases are inherently focused, given that they ask for new information. If the reversal languages employ topic rather than subject agreement and requires the agreeing NP to be always topic, then these languages would not allow a wh-element to agree. We saw this earlier in (1c) from Dzamba. Another (similar) example is given in (15). The same holds for other reversal languages like Kinyarwanda as shown in (16). Chichewa on the other hand does not permit S-O reversal, and it allows $w h$-subjects in situ, as shown in (17)). ${ }^{10}$
(15) *Nzányí ó-wimol-aki ó-Biko e-kondo loэ mé?
Dz. $w h$-subject in situ
'Who told Biko a story/tale today?'
(Bokamba 1981)

\footnotetext{
${ }^{9}$ The alternation of the class 1 agreement $a-y$ seems to be phonologically conditioned.

${ }^{10}$ Sam Mchombo (p.c, January 2003) points out that the verb in (17) has high tones as indicated, which signal extraction of the wh-element. In other words, this question still appears to retain the tonal property of the cleft construction (which is built on relativization in Bantu, according to Bresnan and Mchombo 1987) that is typically used to form a subject wh-question in Bantu. It could be that the tonal distinction on the verb remains merely as a historical source of what used to be the cleft required for a subject $w h$-question.
} 
(16) *Nde y-a-som-ye igitabo?

who SM-PAST-read-ASP book

'Who read the book?'

Krw $w h$-subject in situ

(17) (Kodí) chíyâni chi-ná-ónek-a?

Q what(7) SM(7)-PAST-happen-INDIC

'What happened?'

Chichê̂a $w h$-subject in situ

If we uniformly assume subject agreement across the whole family, then these facts would be left unexplained. If we assume, instead, that reversal languages display topic agreement, the ungrammaticality of (15)-(16) would be an obvious consequence of the system.

Verb-object idioms: In idiomatic expressions consisting of a verb and its object such as (18) in German, the object is non-referential, and as such they can never be topic.

(18) a. das Kind mit dem Bade ausschütten

'to throw the baby with the bath water'

b. Viele Köche verderben den Brei.

'(Too) many cooks spoil the meal.'

If these idiomatic objects can be passive subjects and still maintain the idiomatic interpretation, then it would show that the language allows non-topical, nonreferential subjects. Now, German has a non-referential expletive subject es, as in es regnet 'it is raining'. And we see in (19) that the objects in these verb-object idioms can be passivized subjects without losing the idiomatic interpretation.

(19) a. Das Kind wurde mit dem Bade ausgeschüttet.

'The baby got thrown with the bath water.'

b. Der Brei wird von vielen Köchen verdorben.

'The meal gets spoiled by (too) many cooks.'

In Chicheŵa, we also find verb-object idioms, as exemplified in (20a). The grammaticality of (20b) shows that Chichewa allows the objects of verb-object idioms to be passivized (Bresnan and Mchombo 1987:763). 
(20) a. Chifukwá chá mwáno wâke Mavútó tsópáno because of rudeness his Mavuto now a-ku-nóng'ónez-a bôndo.

SM-PRES-whisper.to-INDIC knee

'Because of his rudeness, Mavuto is now whispering to his knee (= feeling remorse).'

b. Bôndo li-ná-nóng'onez-ědw-a.

knee(5) SM(5)-PAST-whisper.to-PASS-INDIC

'The knee was whispered to (= the remorse was felt).'

Chichewa also has a few proverbs that involve idiomatic subjects, exemplified in (21) from Bresnan and Mchombo (1987).

(21) a. Kalulu a-na-mu-omba maondo.

Hare SM-PAST-OM-knock knees

'The hare knocked him in the knees.'

(= He has stiff knees which cannot bend.)

b. Njovu i-na-ponda-po.

Elephant 9SM-PAST-step-LOC.ENCL

'The elephant stepped on it (hence rendered it dysfunctional).' Chicheŵa

Again in such expressions, the subject is non-referential; hence it cannot be topical. These data therefore show that subjects in Chichewa need not be topical or even referential. This is not true of reversal languages, as illustrated in (22) from Kirundi. The data in (22) are consistent with those of another reversal language, Dzamba, which requires the agreeing preverbal NP to be topic as we have already seen in (15).

(22) a. Yohani a-a-ra-hend-ye

umunwa.

John 1SM-PAST-AF-cheat/mislead-PERF mouth

(lit.) 'John cheated/misled the mouth.'

(= 'John ate almost nothing.')

b. *Umunwa u-a-ra-hend-u-ye (na Yohani). mouth SM-PAST-AF-cheat/mislead-PASS-PERF by John (lit.) 'The mouth was cheated/misled (by John).' (= 'Almost nothing was eaten (by John).')

In short, these data on idiomatic expressions also reveal different agreement properties that are unexplained by the uniform subject analysis. 
Agentive object without verbal morphology

Apart from the above facts that are unaccounted for in the subject analysis, it is also worth pointing out that it is typologically quite rare for an agent to be linked to the object function without any morphology accompanying such unusual linking (also argued by Lødrup 1999). And this would be precisely the claim made by the subject analysis.

Now in ergative languages, the more patient-like argument $(\mathrm{O})$ is linked to the most unmarked absolutive case, along with the sole argument of the intransitive predicate (S). The agent of the transitive (A) is linked to the marked ergative case. The linking patterns of $\mathrm{A}, \mathrm{S}$, and $\mathrm{O}$ are thus said to be the inverse of those in nominative-accusative languages (cf. Manning 1996). Similarly in Austronesian languages, the unmarked linking pattern is one in which the patient-like argument is linked to nominative (e.g. ang-marking in Tagalog; cf. Kroeger 1993).

These inverse linking types, however, display rich case/verbal morphology. Bantu languages share no typological properties with these language types. It is therefore not reasonable to assume that ergative/Austronesian type linking is shared by (a subset of) Bantu languages without any morphology.

To summarize, in this section I hope to have shown that the predominantly held view of S-O reversal represented by the subject analysis is untenable, firstly because there is no reliable evidence for the assumed grammatical relation change, and secondly because it fails to provide a coherent explanation of the set of covariation observed in the reversal and non-reversal languages.

\section{Salience-Based Agreement vs. Role-Based Agreement}

In this section I provide a sketch of the alternative topic analysis of S-O reversal and agreement patterns across Bantu more generally. The key idea is that Bantu languages exhibit two types of agreement: salience-based and role-based. Furthermore, the observed variation in agreement properties across the synchronic Bantu grammars suggests a historical path from salience-based to role-based agreement.

The idea explored in the topic analysis is that just as arguments are ranked according to the argument hierarchy, they are ranked according to the topicality hierarchy. This hierarchy is determined by relative 'salience' of the arguments, and is distinguished from discourse prominence. The notions of 'topic salience' and 'discourse prominence' are defined in (23). 
(23) a. Topic Salience: Arguments are ranked according to topicality. An argument that is most prominent in discourse is also the most salient in terms of topicality. In the absence of such an argument, by default the nominative argument will be most salient (cf. Givón 1976, Keenan 1976, Li and Thompson 1976).

b. Discourse Prominence: Any element that can bear a (lexical) stress can be discourse-prominent. It may be topical or focal.

Given that the arguments of a given predicate are ranked according to topic salience, naturally there can be at most one argument that is most salient in terms of topicality, while there can be multiple constituents that are discourseprominent. ${ }^{11}$

The claim in (23a) that the nominative argument will be topically the most salient by default is supported by the cross-linguistic characterization of subjects and the historical source of subjects' topic prominence. Givón (1976), for example, notes that subjects in many languages, such as Mandarin, Malagasy, and also Kinyarwanda, must be either definite or generic (see also Keenan 1976, Li and Thompson 1976). This property is reminiscent of (dislocated) topics, which, according to Givón (1976), are universally restricted to be definite or generic (also see Alsagoff 1992:192, Lambrecht 1994, Birner and Ward 1998). Malagasy is an VOS language, and the nominative NP is placed sentence finally and must be topical (= topically the most salient element). However, like most verb-initial languages, the position for discourse-prominent constituents is clause-initial.

Even in so-called subject-prominent languages such as English, which tolerate indefinite, non-referential subjects, subjects are nonetheless overwhelmingly definite and referential (Givón pp.154-155). In English, continuing topic is generally expressed as a subject, but the new topic (discourse-prominent) is expressed in a left-dislocated position. For example in an answer to the question in A below, B would be more natural than $\mathrm{B}^{\prime}$, as shown in (24), where they (family) is established information:

(24) A: Where does your family live?

B: They live in N.Y.

$\mathrm{B}^{\prime}$ : \#My family, they live in N.Y.

\footnotetext{
${ }^{11}$ By emphasizing lexical stress in (23b), I mean to exclude cliticized unstressed pronouns that cannot be discourse-prominent, as in the German (e)s in ich kann's machen 'I can do it' or the English 'im in I got'im (I got him).
} 
On the other hand, as a continuation of the above exchange, if B wanted to mention where his/her cousin lives as opposed to his family, then an utterance like that of $\mathrm{B}^{\prime}$ in (24) becomes most felicitous. In this context, cousin in (25) is introduced as a new topic contrasting with the old topic family.

(25) B: (Now) my cousin, he lives in Chicago.

$\mathrm{B}^{\prime}$ : \#(Now) he lives in Chicago, my cousin.

$\mathrm{B}^{\prime \prime}$ : (Now) my COUSIN lives in Chicago.

(OK with appropriate intonation)

Thus, a dislocated topic is used as a new/contrastive topic, while the old topic tends to be expressed as a clause-internal topic or the subject in a non-dislocated subject construction. Birner and Ward (1998) make a similar pragmatic difference between English dislocation and topicalization based on a large number of corpus data. I assume therefore that topic salience is universally part of the argument linking domain. Following the system of abstract case features familiar in Lexical Decomposition Grammar (e.g. Wunderlich 2000), I represent topic salience by a binary feature $[ \pm \mathrm{ht}]$, as shown in $(26 \mathrm{a}, \mathrm{b})$. The feature $[-\mathrm{ht}]$ states that "there is no argument that is higher in topic salience", and specifies the element in highest topic salience. Conversely, [+ht] states that "there is an argument that is higher in topic salience". These features form a universal scale as shown in (26c), which I refer to as the TOPICALITY HIERARCHY.

(26) Encoding topic salience (á la Wunderlich 2000)

a. [-ht]: "There is no other argument that is higher in topicality."

b. [+ht]: "There is another argument that is higher in topicality."

c. Topicality hierarchy: $[-\mathrm{ht}]>[+\mathrm{ht}]$

In terms of these feature specifications, topic-prominent languages can be said to link [-ht] (topically most salient) to subject; subject-prominent languages, on the other hand, link [-hr] (highest argument) to subject. Within this system, we can say that subject is cross-linguistically the default topic because [-ht] is assigned to the argument with the $[-\mathrm{hr}]$ feature $^{12}$ by default when context identifies none of the arguments as topically salient (or non-salient).

Returning to the Bantu agreement systems, we can characterize S-O reversal languages as having salience-based topic marking in the sense that the agreement prefix encodes the most topical, but not necessarily the highest, ar-

\footnotetext{
${ }^{12}[-\mathrm{hr}]$ reads as "there is no argument that is higher in the argument hierarchy, and is assigned to the highest role.
} 
gument. We might represent this property of the topic agreement in a lexical entry like that in (27). These functional schemata, familiar from LFG, specify that there is some feature structure $\left(f_{1}\right)$ that contains a grammaticized discourse topic 'TOP', whose value is another feature structure $\left(f_{2}\right)$. This inner feature structure contains the information specified by the topic marker (TM), gender and number. The optional semantic content SEM $=$ 'pro' abbreviates two feature structures, one with 'pro', which represents a TM functioning as a topic pronoun, and the other without 'pro', representing a TM as topic agreement.

(27) Lexical entry of the topic marker (TM)

$$
\begin{array}{cc}
\text { TM-: } \quad \mathrm{V}_{\text {infl }} \quad\left(f_{1} \text { TOP }\right)=f_{2} \\
\\
\left(f_{2} \text { GEND }\right)=\alpha \\
\left(f_{2} \text { NUM }\right)=\beta \\
\left(\left(f_{2} \text { SEM }\right)=\text { 'pro' }\right)
\end{array}
$$

The instantiations of these functional schemata result in the feature structure shown in (28). The curved line from $f_{2}$, the value of TOP, to GF in (28) indicates that the TOPIC is associated with one of the argument selected by the predicate (realized as a core GF). This is ensured by the extended coherence condition of LFG (Bresnan 2001, chapter 4), which requires that grammaticized discourse functions TOPIC and FOCUS be associated with one of the argument functions selected by the predicate.

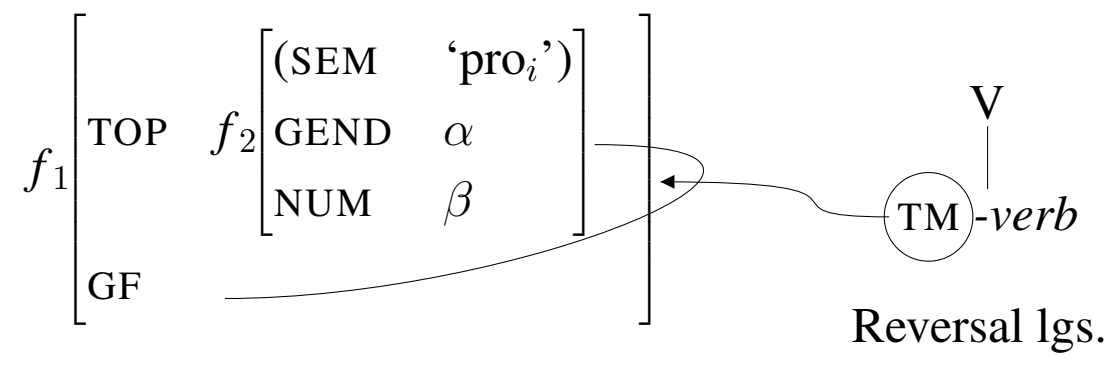

Non-reversal languages like Chichewa employ role-based subject marking: the subject marker (SM) encodes the highest argument in the argument hierarchy. Thus, the lexical entry may contain the information shown in (29). Here the SM specifies that there is some feature structure $\left(f_{1}\right)$ that contains a SUBJ, whose value is identified with another feature structure $\left(f_{2}\right)$. The information included in the inner f-structure is identical to that of the TM in (27). The f-structure in (30) shows the instantiations of these functional schemata. 
(29) Lexical entry of the subject marker (SM)

$$
\begin{array}{cc}
\text { SM-: } \quad \mathrm{V}_{\text {infl }} \quad\left(f_{1} \text { SUBJ }\right)=f_{2} \\
\\
\left(f_{2} \text { GEND }\right)=\alpha \\
\left(f_{2} \text { NUM }\right)=\beta \\
\left(\left(f_{2} \text { SEM }\right)=\right.\text { 'pro') }
\end{array}
$$

(30)

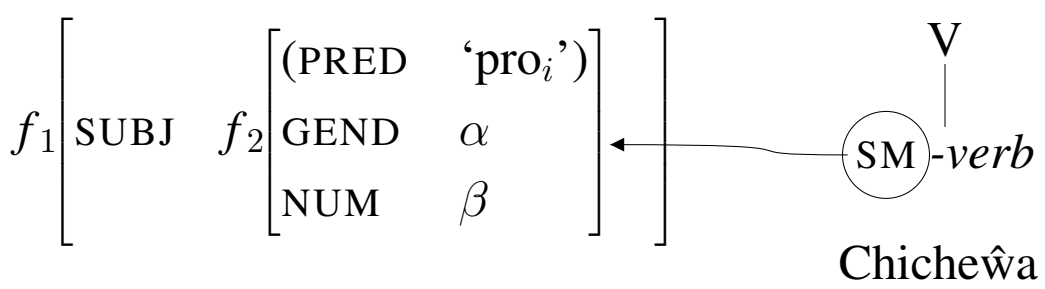

Now there is a third type, namely, languages such as Sesotho and Setswana that do not allow S-O reversal like the salience-based agreement languages, but also do not allow non-topical subjects to agree like the role-based agreement languages (cf. Demuth and Mmusi 1997). In fact, I believe the majority of Bantu languages are described in the literature as belonging to this type.

Within the proposed systems of agreement, we can characterize this third type as having a basically role-based agreement system. The only restriction is that the agreeing subject must be topically salient $([-\mathrm{ht}])$. The f-structure in (31) shows that the TOPIC function is always associated with SUBJ.

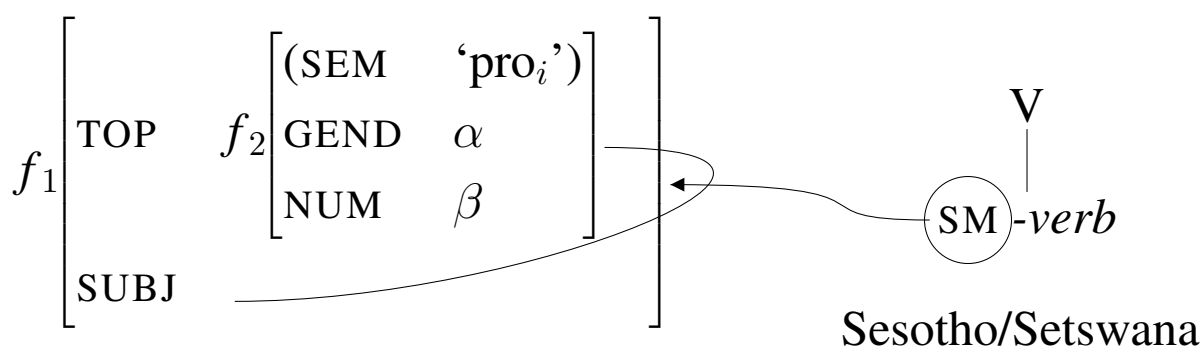

From the diachronic perspective, the Sesotho/Setswana type can be viewed as an intermediate stage in the shift from topic to subject agreement. One piece of supporting data for the supposed historical path that gave rise to the two agreement systems in the present day Bantu languages comes from Meeussen's (1967) reconstruction of Proto-Bantu. Meeussen (1967:120) reconstructs a syntactic pattern in Proto-Bantu that is analogous to S-O reversal (and locative inversion), as illustrated in (32)-(33). These data lead us to infer that the system of topic agreement already existed in Proto-Bantu. ${ }^{13}$

\footnotetext{
${ }^{13}$ The precise translation of (32) is not available in the original source.
} 
(32) a. nkíma jí-1jji buénge búá-mití

$\mathrm{S}(\exp ) \mathrm{SM}-\mathrm{V} \mathrm{O}$ (theme)

b. buénge búá-mití bú-îji nkíma

$\mathrm{O}$ (theme) SM-V S (exp)

'The monkey knows the (cleverness of) trees.'

(33) a. njogư jí-ákựíde mu-duí

$\mathrm{S}(\exp ) \mathrm{SM}-\mathrm{V} \quad$ LOC

'The elephant died in the river.'

b. mu-duí mu-ákứỉide njogư

LOC SM-V S (exp)

'In the river (there) died an elephant.'

The historical path from topic to subject marking suggested by the above data can be attributed to a 'frequentist' explanation recently advocated by researchers like Bybee (Bybee 1998, Bybee and Hopper 2001) and Haspelmath (2005) to explain certain morphosyntactic regularities and change. The apparent change in the agreement systems observed through the synchronic variation across the Bantu family can be seen as an effect of frequency-namely, the notion of subject embodies a frequent combination of semantic and information-structural properties, most prominently a combination of agents and topics. Subject agreement is more iconic than topic agreement in the sense that there is one-to-one correspondence between the agreement morphology and grammatical function (paradigmatic isomorphism, cf. Haiman 1980, Croft 1990a). These functional forces seem to be reasonable motivations for the shift in which the topic agreement was reanalyzed as subject agreement, and consequently the preverbal agreeing NP became restricted to the subject function. We can then also expect a further historical path where all Bantu languages eventually come to employ the role-based agreement system. The expected concomitant change is, of course, the eventual loss of S-O reversal. Additional data on S-O reversal suggest that this may already be happening, as discussed below.

\section{Grammatical Change along Referential Hierarchies}

When the new system replaces the old, it typically does so gradually in a predictable fashion along referential hierarchies. A case in point is split ergativity. Split ergativity is viewed as a transitional synchronic stage in a change from the 
ergative/absolutive system to nominative/accusative system (cf. Dixon 1994). In ergative languages, it is claimed that the higher the NP on the nominal hierarchy in (34), adopted by Dixon (1994:85), the more likely it is to be in A (transitive subject) rather than O (transitive object) function (e.g. Du Bois 1987, Dixon 1994).

$$
\begin{aligned}
& \text { Nominal Hierarchy } \\
& 1 \text { st }>2 \text { nd }>3 \text { rd }>\text { Name }>\text { Human }>\text { Animate }>\text { Inanimate } \\
& \longleftarrow \quad \text { more likely to be in A than in O function }
\end{aligned}
$$

The first person pronoun is therefore said to be the most "prototypical" or "unmarked" A, while the inanimate NP is the most "unmarked" O. Assuming the general markedness principle widely assumed that marked forms are also morphosyntactically marked, what we expect in a split ergative language along this nominal hierarchy is presence of morphological marking of an NP from the lowest element of the hierarchy when it is in A function, but from the highest element in O function. According to Dixon (1994:85), a number of languages have split case-marking systems exactly on this principle: a morphologically overt (="marked") ergative case is used with NPs from the lowest end, up to some point in the middle of the hierarchy, and an accusative case from that point on, over to the highest end of the hierarchy. Split ergativity illustrates thus how a shift from one system to another takes place systematically and predictably along a referential hierarchy.

In the Bantu languages with the salience-based agreement system, we see that S-O reversal is restricted along the dimension of the animacy hierarchy (= a simpler version of the nominal hierarchy in (34)) given in (35).

\section{(35) Animacy hierarchy: Human $>$ Animate $>$ Inanimate}

As in the nominal hierarchy in (34), given two arguments, subject and object, the highest element in the hierarchy (human) is the most "prototypical/unmarked", or - to use the notion of 'frequency' instead-most frequently the subject, while the lowest element (inanimate) is the most frequently the object. Then presumably the most frequent structure (and animacy configuration) would be one such as the boy is reading a book where the subject is human, and the object, inanimate. On the other hand, the least frequent (animacy) configuration would be one like loud noise disturbed the baby, where the subject is inanimate, and the object, human.

As reported by Morimoto (2003), it is these predicates with rare (termed "marked" in Morimoto 2003) animacy relations that block S-O reversal. This 
is exemplified in (36)-(37). ${ }^{14}$ Example (36) (presumably) represents the least frequent animacy configuration, where the subject is inanimate and the object is human. As shown in the translation for (36), the reversal reading is blocked. The $b$ sentence is grammatical only in the non-reversal, non-sensical reading. In (37), the subject is also lower in animacy, and again, the reversal reading is blocked in the $\mathrm{b}$ sentence.

(36) a. Urushiinge ru-ra-joomb-a umwaana.

$S=$ inanimate needle it-AF-pierce-ASP child

$\mathrm{O}=$ human

'The needle will pierce the child.'

b. Umwaana a-joomb-a urushiinge.

*reversal child he-pierce-ASP needle *'The needle ${ }_{F O C}$ will pierce the child ${ }_{T O P}$.'

Kinyarwanda

$\begin{array}{lr}\text { a. Akayabu ka-a-ra-fyese umuhungu. } & \mathrm{S}=\text { animate } \\ \text { cat it-PAST-AF-lick:PERF boy } & \mathrm{O}=\text { human }\end{array}$ 'The cat licked the boy.'

b. Umuhungu a-a-fyese akayabu. *reversal boy he-PAST-lick:PERF cat

*'The cat ${ }_{F O C}$ licked the boy $_{T O P}$.'

Kirundi

When the arguments are of equal animacy and there is potential ambiguity in interpretation, as in (38), the reversal interpretation is unavailable just from the string (in a null context); the only possible meaning in (38b) is one in which umukoôwa 'girl' is the subject/agent, and umuhuûngu 'boy' is the object/patient.

(38) a. Umuhuûngu y-a-som-ye umukoôwa.

$\mathrm{S}=$ human

1boy 1-PST-kiss-ASP 1 girl

$\mathrm{O}=$ human

'The boy kissed the girl.'

b. Umukoôwa y-a-som-ye umuhuûngu.

1 girl 1-PST-kiss-ASP 1 boy

'The girl kissed the boy.' (no reversal)

*'The boy ${ }_{F O C}$ kissed the $\operatorname{girl}_{T O P}$.' (reversal) Kinyarwanda

On the other hand reversal is allowed in an example like (39) where only one of them can be the likely subject/agent due to the core meaning of the verb.

\footnotetext{
${ }^{14}$ The examples in (36)-(39) are taken from Morimoto (2003).
} 

a. Icyuma cy-a-kas-e umugaati.
$\mathrm{S}=$ inanimate
knife it-PST-cut-ASP bread
$\mathrm{O}=$ inanimate

'The knife cut the bread.'

b. Umugati w-a-kas-e icyuma.

$\sqrt{ }$ reversal

bread it-PST-cut-ASP knife

'The knife ${ }_{F O C}$ cut the bread ${ }_{T O P .}$.'

Kinyarwanda

In short, S-O reversal is permitted when the subject outranks the object in animacy, but not when the subject is lower in animacy than the object. When there is equal animacy and ambiguity results, the reversal interpretation becomes unavailable. These facts are summarized in (40).

(40) Grammatical Function-Animacy Association in S-O Reversal

\begin{tabular}{c|c|c|c|c|}
\multicolumn{5}{c}{ OBJ } \\
\cline { 2 - 5 } & & HUM & ANIM & INAN \\
\cline { 2 - 5 } SUBJ & yes & yes & yes \\
\cline { 2 - 5 } & ANIM & no & yes & yes \\
\cline { 2 - 5 } & INAN & no & no & yes* \\
\cline { 2 - 5 }
\end{tabular}

yes*: only if there is no ambiguity

The rationale for the facts summarized in (40) seems straightforward: on the one hand, the configuration in which object outranks subject in animacy is less frequent than the one in which subject outranks object. On the other hand, S-O reversal sentences are non-canonical—presumably also rarer in frequency-both syntactically (non-canonical ovs order) and pragmatically (patient is topical and agent is focal), than the non-reversal counterparts. The descriptive generalization, then, is that the less frequently occurring animacy relations cannot be expressed in the non-canonical syntactic construction (reversal). ${ }^{15}$ This type of non-canonical form-meaning pairs that are not likely to appear frequently in the language (or blocked altogether as in the present case) seems to be susceptible to change/loss over time (cf. Croft 1990b). ${ }^{16}$

In short, the animacy restriction on S-O reversal suggests this construction is being lost from the least frequent combination of elements in the referen-

\footnotetext{
${ }^{15}$ See Morimoto (2001) for an OT analysis of these facts.

${ }^{16}$ Animacy also figures in the domain of differential object marking (DOM; cf. Bossong 1985, Aissen 2003), in which objects that are high in animacy are case-marked, while those low in animacy are unmarked. Like split ergativity, DOM is also said to represent a stage in the diachronic process whereby overt case-marking is being lost from the low end of the referential hierarchy.
} 
tial and argument hierarchy (e.g. inanimate-subject, human-object). And this change must be concomitant to the change in the properties of the agreement morphology. Properly recognizing the two systems in the Bantu family, the salience-based and role-based, then enables us to relate the relevant synchronic data like the animacy restriction on S-O reversal, inventory of non-topical subjects to the issue of agreement and to a diachrony of the agreement systems.

\section{Conclusion}

In this final section I summarize the findings and main issues discussed in this paper, and then point out some remaining issues for future work.

\subsection{Summary}

In this paper, I have argued for the two-fold agreement systems in Bantu: salience-based agreement and role-based agreement. The crucial evidence for salience-based agreement comes from the existence of S-O reversal, where the preverbal patient triggers topic, rather than subject, agreement. The subject analysis of this construction that assumes grammatical relation change was rejected on both empirical and theoretical basis. I have shown that the proposed view of agreement better explains the set of covariation related to the presence/absence of S-O reversal.

I have also tried to relate the synchronic data to the historical path from topic to subject agreement, which I suggest is a particular realization of the more general functional shift from topic to subject. Referential properties like animacy seem to figure in diachronic change, as attested in split ergativity and differential object marking. The animacy restriction on S-O reversal thus probably represents a stage in the gradual loss of this construction, concomitant with the shift from topic to subject agreement.

In conclusion, in order to provide a coherent explanation of the set of facts related to S-O reversal and to relate those facts to a broader set of agreement phenomena (split ergativity, DOM), it is crucial that we recognize the role of topicality in the core grammar, as manifested in topic agreement.

\subsection{Remaining Issues}

The present proposal that Bantu languages split between topic and subject agreement has naturally opened doors to new issues and problems, some of which are clearly beyond the scope of this paper. Below I address a few note- 
worthy issues for future work. ${ }^{17}$

First, given the claim that a subset of Bantu languages display topic agreement, we should expect more differences between topic agreement and subject agreement languages than those discussed in section 2. For example, Kinyarwanda has four pleonastic pronouns (only for subjects) that are used in impersonal constructions. Under the topic agreement analysis, one would need additional explanation of how such impersonal pronouns can exist at all. Kimenyi (1980:185) notes that one of these pleonastic pronouns that refers to an unspecified agent, $b a$ - ('they'), always has ambiguous interpretation as a 'dummy' pronoun and a definite personal pronoun. There are also cases where this pronoun must be interpreted as a definite, topic-anaphoric pronoun. It would be worthwhile to examine the properties of these impersonal pronouns in both topic agreement and subject agreement languages.

Second, from the historical perspective, it is interesting to note that while $\mathrm{S}-\mathrm{O}$ reversal is restricted to only a subset of Bantu languages, locative inversion remains widespread throughout this language family. As we have seen, S-O reversal generally involves inversion of a proto-typical agent and patient. The animacy condition we saw in section 4 limits S-O reversal to only a subset of predicates. Such a split within the construction makes the overall frequency of S-O reversal relative low compared to a construction without such a split (due to the animacy restriction). It might well be that the decrease in overall frequency has led to the total loss of this construction in the majority of the Bantu languages. To pursue this view, one would have to examine quantitative data on S-O reversal as well as locative inversion.

Lastly, in order to establish a more solid argument for the existence of topic agreement, more contextualized data (e.g. from text) would perhaps be necessary.

Nonetheless, I hope that the present discussion on the split between subject and topic agreement across the Bantu family serves as a step forward towards a better understanding of the relation between agreement properties and word order in Bantu.

\section{References}

Aissen, J. (2003). Differential case marking: Iconicity vs. economy. Natural Language \& Linguistic Theory, 21:435-483.

Alsagoff, L. (1992). Topic in Malay: The Other Subject. Ph.D. thesis, Stanford University, Stanford, CA.

\footnotetext{
${ }^{17}$ The remaining issues addressed here have been prompted by the editors of this volume.
} 
Birner, B.J. \& Ward G. (1998). Information Status and Noncanonical Word Order in English. Studies in Language Companion Series. Amsterdam/Philadelphia: John Benjamins.

Bokamba, E.G. (1976). Question Formation in Some Bantu Languages. Ph.D. thesis, Indiana University, Indiana.

Bokamba, E.G. (1979). Inversions as grammatical relation changing rules in Bantu. Studies in the Linguistic Sciences, 9:1-24.

Bokamba, E.G. (1981). Aspects of Bantu Syntax. Preliminary edition. Department of Linguistics, University of Illinois, Urbana-Champaign, Illinois.

Bokamba, E.G. (1985). Verbal agreement as a noncyclic rule in Bantu. In: D.L. Goyvaerts (ed.) African Linguistics: Essays in memory of M.W.K Semikenke, 9-54. Amsterdam/Philadelphia: John Benjamins.

Bossong, G. (1985). Differentielle Objektmarkierung in den neuiranischen Sprachen. Tübingen: Gunter Narr Verlag.

Bresnan, J. (ed.) (1982). The Mental Representation of Grammatical Relations. Cambridge, MA: The MIT Press.

Bresnan, J. (1994). Locative inversion and universal grammar. Language, 70:72-131.

Bresnan, J. (2001). Lexical-Functional Syntax. Oxford: Blackwell Publishers.

Bresnan, J. \& Kanerva J.M. (1989). Locative inversion in Chicheŵa: A case study of factorization of grammar. Linguistic Inquiry, 20(1):1-50.

Bresnan, J. \& Mchombo S.A. (1987). Topic, pronoun, and agreement in Chicheŵa. Language, 63:741-782.

Bybee, J. (1998). A functionalist approach to grammar and its evolution. Evolution of Communication, 2:249-278.

Bybee, J. \& Hopper, P. (2001). Frequency and the emergence of linguistic structure. Amsterdam: John Benjamins.

Croft, W. (1990a). Possible verbs and the structure of events. In: S. Tsohatzidis (ed.) Meanings and prototypes: Studies in linguistic categorization, 48-73. London: Routledge.

Croft, W. (1990b). Typology and Universals. Cambridge Textbooks in Linguistics. Cambridge: Cambridge University Press. 
Dalrymple, M., Kaplan, R.M., Maxwell, J.T., \& Zaenen A. (eds.) (1995). Formal Issues in Lexical-Functional Grammar. Stanford, CA: CSLI Publications.

Demuth, K. \& Mmusi, S. (1997). Presentational focus and thematic structure in comparative Bantu. Journal of African Languages and Linguistics, 18:1-19.

Dixon, R.M. (1994). Ergativity. Cambridge, MA: Cambridge University Press.

Du Bois, J.W. (1987). The discourse basis of ergativity. Language, 63:805-855.

Falk, Y.N. (1983). Subjects and long-distance dependencies. Linguistic analysis, 12:245-270.

Gazdar, G. (1981). Unbounded dependencies and coordinate structure. Linguistic Inquiry, 12:155-184.

Givón, T. (1976). Topic, pronoun, and grammatical agreement. In Li (1976), 149-188.

Haiman, J. (1980). The iconicity of grammar. Language, 56:515-540.

Harford, C. (1990). Locative inversion in Chishona. In: J.P. Hutchison \& V. Manfredi (eds.) Current Approaches to African Linguistics, volume 11, 137-144. Dordrecht: Foris Publications.

Haspelmath, M. (2005). Against markedness (and what to replace it with). MS. Max-Planck-Institut für evolutionäre Anthropologie.

Joshi, S. (1993). Selection of Subjects and Objects in Marathi. Ph.D. thesis, Stanford University, Stanford, CA.

Keenan, E. (1976). Towards a universal definition of "subject". In Li (1976), 303-333.

Kimenyi, A. (1980). A Relational Grammar of Kinyarwanda. Berkeley, CA: University of California Press.

Kimenyi, A. (1988). Passives in Kinyarwanda. In: M. Shibatani (ed.) Passive and Voice, 355-386. Amsterdam/Philadelphia: John Benjamins.

Kinyalolo, K.K.W. (1991). The SPEC-Head Agreement Hypothesis in KiLega. Ph.D. thesis, University of California Los Angeles, Los Angeles, CA.

Kroeger, P. (1993). Phrase Structure and Grammatical Relations in Tagalog. Dissertations in Linguistics. Stanford, CA: CSLI Publications.

Lambrecht, K. (1994). Information Structure and Sentence Form. Cambridge, UK: Cambridge University Press. 
Li, C. (ed.) (1976). Subject and Topic. New York: Academic Press.

Li, C.N. \& Thompson, S.A. (1976). Subject and topic: A new typology of language. In: C. Li (ed.) Subject and Topic, 457-489. New York: Academic Press.

Lødrup, H. (1999). Linking and Optimality in the Norwegian presentational focus construction. Nordic Journal of Linguistics, 22:205-230.

Machobane, M.M. (1995). The Sesotho locative constructions. Journal of African Languages and Linguistics, 16:115-136.

Manning, C.D. (1996). Ergativity: Argument Structure and Grammatical Relations. Dissertations in Linguistics. Stanford, CA: CSLI Publications.

Meeussen, A. (1967). Bantu grammatical reconstructions. Africana Linguistica III, 61:79-121. Tervuren Belgique Royal Museee de L'afrique: Sciences Humaines Annales.

Morimoto, Y. (1999). An Optimality account of argument reversal. In: M. Butt \& T.H. King (eds.) Proceedings of the LFG '99 Conference. Stanford, CA: CSLI Publications. http://csli-publications.stanford.edu/ LFG/4/lfg99.html.

Morimoto, Y. (2000). Discourse Configurationality in Bantu Morphosyntax. $\mathrm{Ph} . \mathrm{D}$. thesis, Stanford University, Stanford, CA.

Morimoto, Y. (2002). Prominence mismatches and differential object marking in Bantu. In: M. Butt \& T.H. King (eds.) Proceedings of the LFG-02 Conference. Stanford, CA: CSLI Publications. http:// csli-publications.stanford.edu/LFG/6/lfg02.html.

Morimoto, Y. (2003). Markedness hierarchies and optimality in Bantu. In: R. Laury, G. McMenamin, S. Okamoto, V. Samiian, \& K. Subbarao (eds.) Perspectives in Linguistics: Papers in Honor of P.J Mistry, 261-280. New Delhi: Indian Institute of Language Studies.

Ndayiragije, J. (1999). Checking economy. Linguistic Inquiry, 30:399-444.

Stucky, S. (1981). Word Order Variation in Makua: A Phrase Structure Grammar Analysis. Ph.D. thesis, University of Illinois, Urbana, IL.

Stucky, S. (1983). Verb phrase constituency and linear order in Makua. In: G. Gazdar (ed.) Order, Concord, and Constituency, 75-94. Dordrecht: Foris.

Ura, H. (1996). Multiple Feature Checking. Ph.D. thesis, MIT, Cambridge, MA. 
Wald, B. (1979). The development of the Swahili object marker: A study of the interaction of syntax and discourse. In: T. Givón (ed.) Discourse and Syntax, volume 12 of Syntax and Semantics, 505-524. New York: Academic Press.

Williams, E.S. (1977). Across-the-board application of rules. Linguistic Inquiry, 8:419-423.

Woolford, E. (1987). An ECP account of constraints on across-the-board extraction. Linguistic Inquiry, 18:166-171.

Wunderlich, D. (2000). Predicate composition and argument extension as general options-a study in the interface of semantic and conceptual structure. In: B. Stiebels \& D. Wunderlich (eds.) Lexicon in Focus, 249-272. Berlin: Akademie Verlag. 